\title{
Liocourt's law for tree diameter distribution in forest stands
}

\author{
Nicolas Picard ${ }^{1} \cdot$ David Gasparotto $^{2}$
}

Received: 27 March 2016 / Accepted: 20 May 2016 / Published online: 17 June 2016

(C) INRA and Springer-Verlag France 2016

\begin{abstract}
Key message Liocourt's legacy for the law on steadystate uneven-aged forests has been questioned. We propose a new interpretation of his results published in 1898 and refer to a manuscript dated 1900 to clarify that he established this law.

Context Liocourt's law states that in steady-state unevenaged forests, the number of trees in successive diameter classes of equal width form a decreasing geometric series. When referring to this law, most authors cite a paper by Liocourt published in 1898 . The 1898 paper does not contain any explicit mathematical expression, but its results can be interpreted as supporting a geometric series with ratio 2 . Aims We reviewed Liocourt's paper of 1898 to provide a new mathematical interpretation of his results, and reviewed other texts by Liocourt to identify the origin of his law.

Results The paper of 1898 supports a polynomial expression of degree 4 rather than a geometric series. The geometric series was explicitly introduced by Liocourt in a handwritten text dated 1900 that remains little-known.
\end{abstract}

Handling Editor: Jean Daniel Bontemps

Contribution of the co-authors NP did the analysis and wrote the paper; DG provided the information and reviewed the paper

Nicolas Picard

nicolas.picard.1991@ polytechnique.org

1 Via della Sforzesca 1, 00185 Roma, Italy

2 AgroParisTech, 14 rue Girardet, CS14216, 54042 Nancy Cedex, France
Conclusion The 1898 text by Liocourt was a preliminary work on his law that was expressed in its current form in the manuscript dated 1900 .

Keywords de Liocourt's law · de Liocourt $q$ - Diameter distribution - Exponential distribution · Uneven-aged forest

\section{Introduction}

François Henri de Lallemant de Liocourt, born on the 30 August 1860 in Lunéville, France, was a forest engineer who is known under the name of François de Liocourt for his work on the management of silver fir forests. He was attributed by many authors the following result (Schaeffer et al. 1930; Marín-Pageo and Rapp-Arrarás 2013): in steady-state uneven-aged forests, the number of trees in successive diameter classes of equal width form a decreasing geometric series with ratio $1 / q$, where $q$ is real number $>1$. The geometric series of the number of trees in diameter classes is the discrete equivalent of a negative exponential diameter distribution, a model that is often appropriate for inverse-J shaped distributions. Often referred as 'Liocourt's law' or 'Liocourt's $q$ ', this result is important as it is the theoretical basis for sustainable management of uneven-aged forest stands. Liocourt's law first describes the distribution of diameters in natural unmanaged forests, where the number of trees in a diameter class results from the demographic balance between recruitment, upgrowth transitions (from the previous class and to the next one) and mortality. A management system where harvest maintains this distribution of diameters is supposed to 
maintain the demographic balance between recruitment, growth and mortality (including harvest), and is thus considered as sustainable. First developed for monospecific temperate forests, preferentially growing in mountains, Liocourt's law has proven relevant for many different types of natural forests. In particular, it is also the basis for the sustainable management of natural tropical rain forests with periodical selective logging (Vannière 1977).

In a recent review dedicated to Liocourt's work, Kerr (2014) questioned Liocourt's legacy, and advocated that the discovery of the geometry series with ratio $1 / q$ as a general distribution for steady-state uneven-aged forest stands has unduly been attributed to Liocourt. Kerr's analysis relied on a single paper by Liocourt, published in 1898 in the quarterly bulletin of the forest society of Franche-Comté and Belfort (Bulletin de la Société Forestière de FrancheComté et Belfort; see permanent URL to a numeric copy of this work in the reference list). Yet, another handwritten manuscript by Liocourt dating from 1900 also dealt with the diameter distribution of silver fir forests (see permanent URL in the references). Liocourt died in 1928 and the textbook on silver fir forests by Schaeffer et al., published in 1930 in French, was dedicated to his memory. Schaeffer et al. (1930) were among the first to disseminate Liocourt's $q$, citing both his 1898 article and his 1900 handwritten manuscript. Later textbooks often referred only to the 1898 article (Smith 1962).

Based on both the 1898 and 1900 texts by Liocourt, this study aims at examining whether Liocourt defined the $q$ ratio for diameter distributions. We give a new interpretation of the 1898 paper, as an alternative to Kerr (2014)'s proposal and compatible with Liocourt's data, and give excerpts from the 1900 manuscript that clearly document that Liocourt established the $q$ ratio.

\section{Methods and results}

In his 1898 article, Liocourt did not explicitly refer to the $q$ ratio of the numbers of trees between successive diameter classes. However, he defined (p. 403) a typical diameter distribution by the following sequence of numbers of trees in 21 diameter classes with equal width (Table 1): 6217, 5056, 4067, 3232, 2534, 1957, 1486, 1107, 807, 574, 397, $266,172,107,64,37,21,12,7,4,2$. We hereafter call this sequence the Liocourt sequence. The first number is indeed 6217 and not 6216 as reported by Kerr (2014), to comply with the difference between the first and second numbers that is equal to 1161. The question then is: did Liocourt use a geometric series to compute his sequence? Liocourt did not explicitly provide the mathematical expression that he used to compute his sequence, but he provided a twodimensional table (Table 1) and an algorithm (p. 402-403 of
Table 1 Example of a table of numbers $N_{i j}$ defined by recurrence equations (1) and (2)

\begin{tabular}{|c|c|c|c|c|c|c|c|c|}
\hline \multirow{2}{*}{$\begin{array}{r}\text { Row } \\
(i)\end{array}$} & \multicolumn{8}{|c|}{ Column $(j)$} \\
\hline & -2 & -1 & 0 & 1 & 2 & 3 & 4 & 5 \\
\hline-4 & 741482 & 248132 & 68732 & 15302 & 2627 & 326 & 26 & 1 \\
\hline-3 & 549106 & 192376 & 55756 & 12976 & 2326 & 301 & 25 & 1 \\
\hline-2 & 401559 & 147547 & 44829 & 10927 & 2049 & 277 & 24 & 1 \\
\hline-1 & 289709 & 111850 & 35697 & 9132 & 1795 & 254 & 23 & 1 \\
\hline 0 & 205987 & 83722 & 28128 & 7569 & 1563 & 232 & 22 & 1 \\
\hline 1 & 144176 & 61811 & 21911 & 6217 & 1352 & 211 & 21 & 1 \\
\hline 2 & 99220 & 44956 & 16855 & 5056 & 1161 & 191 & 20 & 1 \\
\hline 3 & 67052 & 32168 & 12788 & 4067 & 989 & 172 & 19 & 1 \\
\hline 4 & 44440 & 22612 & 9556 & 3232 & 835 & 154 & 18 & 1 \\
\hline 5 & 28850 & 15590 & 7022 & 2534 & 698 & 137 & 17 & 1 \\
\hline 6 & 18325 & 10525 & 5065 & 1957 & 577 & 121 & 16 & 1 \\
\hline 7 & 11379 & 6946 & 3579 & 1486 & 471 & 106 & 15 & 1 \\
\hline 8 & 6905 & 4474 & 2472 & 1107 & 379 & 92 & 14 & 1 \\
\hline 9 & 4096 & 2809 & 1665 & 807 & 300 & 79 & 13 & 1 \\
\hline 10 & 2378 & 1718 & 1091 & 574 & 233 & 67 & 12 & 1 \\
\hline 11 & 1354 & 1024 & 694 & 397 & 177 & 56 & 11 & 1 \\
\hline 12 & 758 & 596 & 428 & 266 & 131 & 46 & 10 & 1 \\
\hline 13 & 418 & 340 & 256 & 172 & 94 & 37 & 9 & 1 \\
\hline 14 & 227 & 191 & 149 & 107 & 65 & 29 & 8 & 1 \\
\hline 15 & 121 & 106 & 85 & 64 & 43 & 22 & 7 & 1 \\
\hline 16 & 63 & 58 & 48 & 37 & 27 & 16 & 6 & 1 \\
\hline 17 & 32 & 31 & 27 & 21 & 16 & 11 & 5 & 1 \\
\hline 18 & 16 & 16 & 15 & 12 & 9 & 7 & 4 & 1 \\
\hline 19 & 8 & 8 & 8 & 7 & 5 & 4 & 3 & 1 \\
\hline 20 & 4 & 4 & 4 & 4 & 3 & 2 & 2 & 1 \\
\hline 21 & 2 & 2 & 2 & 2 & 2 & 1 & 1 & 1 \\
\hline 22 & 1 & 1 & 1 & 1 & 1 & 1 & 0 & 1 \\
\hline 23 & -1 & 2 & -1 & 2 & -1 & 2 & -1 & 1 \\
\hline 24 & -11 & 10 & -8 & 7 & -5 & 4 & -2 & 1 \\
\hline 25 & -48 & 37 & -27 & 19 & -12 & 7 & -3 & 1 \\
\hline 26 & -154 & 106 & -69 & 42 & -23 & 11 & -4 & 1 \\
\hline
\end{tabular}

The numbers specifying the boundary conditions are shown in gray cells. The part of the table given by Liocourt (1898, p. 403) is surrounded by a line and shown with bold numbers. Column $N_{i 1}$ corresponds to the predicted diameter distribution that fits the observed distribution. The lowest class of observations corresponds to row $i=5$ with a minimum diameter of $20 \mathrm{~cm}$. The width of the classes is $5 \mathrm{~cm}$

his paper) that helps understanding how he proceeded. The number $N_{i j}$ at the $i$ th row and $j$ th column of the table is the difference between the elements at the $(i-1)$ th and $i$ th rows of the $(j-1)$ th column:

$N_{i j}=N_{i-1, j-1}-N_{i, j-1}$

Moreover, the elements in the fifth column are all equal to one. The indications given by Liocourt are not sufficient to identify a unique mathematical formula that would generate his sequence, because the boundary conditions that are 
Fig. 1 Excerpt from Liocourt's manuscript of 1900: a excerpt at page 13 showing the number of trees per diameter class (Table C) and the ratios of the numbers of trees in successive classes (Table D, calculated from Table C). The different columns of these tables correspond to different forest types. The text between the two tables translates as: "We derive [from Table C], in Table $\mathrm{D}$, the ratio between the number of trees in different diameter classes, for each of the seven [forest] types"; $\mathbf{b}$ except at page 14 that immediately follows the excerpt at page 13. It translates as: "One can notice that these ratios are approximately constant, for all forest types and all diameters. The mean of these 88 ratios is 1.4. As it is truly resulting from observations performed on forests of all kinds located in very contrasted soil, elevation and richness conditions, it must be considered as a general rule for the progression from a category of diameter to another and should be applied in any case considered" a Eablean C.

\begin{tabular}{|c|c|c|c|c|c|c|c|}
\hline Diamithen & $\begin{array}{l}\text { Fowats } \\
0.00 \\
0.80\end{array}$ & 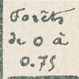 & $\begin{array}{c}\text { Fosith } \\
\text { 200 } \\
0.70\end{array}$ & $\begin{array}{l}\text { Fona } \\
\text { o.o. } \\
0.65\end{array}$ & $\begin{array}{l}F_{00} i 5 \\
\text { oco } \\
0.60\end{array}$ & \begin{tabular}{|l}
$\sigma_{0} .25$ \\
30.5 \\
0.55 \\
0.58
\end{tabular} & $\begin{array}{l}\sigma_{02}=5 \\
\text { ous } \\
0.50\end{array}$ \\
\hline 0.20 & 186 & 217 & 276 & 261 & 291 & 326 & 311 \\
\hline $0 . y$ & 135 & 162 & 180 & 184 & 205 & 215 & 236 \\
\hline 0.30 & 124 & 137 & 143 & iss & 159 & 170 & 196 \\
\hline 0.35 & 98 & 106 & 101 & i15 & 115 & 115 & 117 \\
\hline 0.40 & 92 & 96 & go & 94 & 91 & 80 & 78 \\
\hline 0.45 & 83 & $7 / 4$ & 65 & 69 & 59 & $\int 2$ & 39 \\
\hline 0.50 & 76 & 60 & 53 & 53 & 41 & 28 & 23 \\
\hline $0.3 s$ & 61 & 47 & 35 & 33 & 24 & 14 & " \\
\hline 0.60 & 47 & 37 & 27 & 22 & is & " & " \\
\hline 0.65 & 39 & 31 & 18 & 14 & 4 & " & " \\
\hline 0.70 & 28 & 21 & 12 & " & • & " & ", \\
\hline 0.75 & 18 & 12 & " & . & " & " & , \\
\hline 0.80 & 13 & " & " & .. & ' & "I & .. \\
\hline & & & & & & & \\
\hline & & & & & & & \\
\hline
\end{tabular}

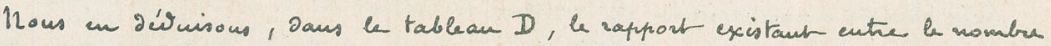

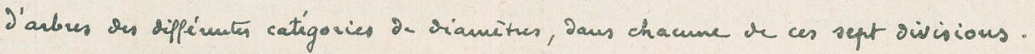

$$
\text { Gablean D. }
$$

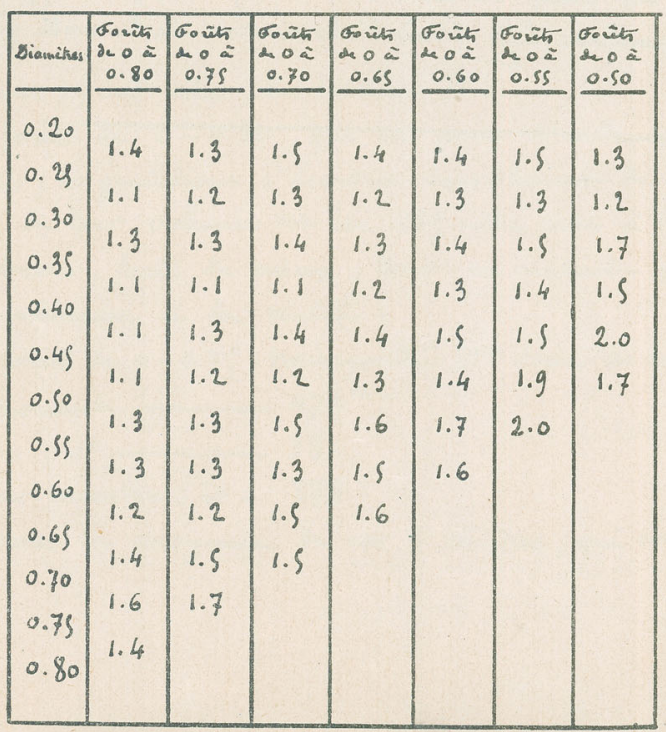

b

On remarque que ces rapposts sout à pres pines constants, quels que soimh la catigorie de foîts et le Tiansitre envisagés.

La noyeune de en 88 rappoit est de 1,4.

Conume elle est la résultante légitime d'descuvations faites sur des

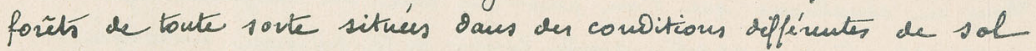
g'altiture et de richesse, cle doit être consisírie conume étant

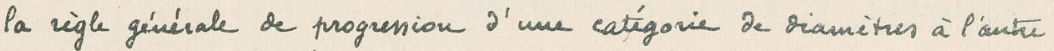
devaut cthe appliquée sans tous les cas à envisager. 
necessary to complement the recurrence equation (1) were not specified. Kerr (2014) considered that the recurrence equation (1) was used to add columns to the table from right to left, each extra column being computed from bottom to top. This computation requires the number of trees in the largest diameter class to be given as a boundary condition for each added column. Kerr (2014) pointed out that this boundary number was 1 in Liocourt's table for the three leftmost columns, but then unexpectedly changed to 2 for the subsequent columns. Kerr noticed that no explanation for this change was provided by Liocourt.

We here provide an alternative interpretation of Liocourt's table that consists in considering that the table was built row-wise (from top to bottom) instead of columnwise. Equation (1) can be interpreted as the finite difference approximation of a first-order derivative. From left to right, each column in Liocourt's table then corresponds to the derivative of the previous column. Therefore, the fifth rightmost column is the finite difference approximation of the derivative of order 4 of the first leftmost column. Equating the fifth column to one thus brings a fourth order recurrence equation:

$N_{i 1}-4 N_{i+1,1}+6 N_{i+2,1}-4 N_{i+3,1}+N_{i+4,1}=1$

where the coefficients are those of the central finite difference to approximate a derivative of order 4 . The numbers of Liocourt's sequence obey this mathematical model. Four boundary numbers are necessary to initiate this sequence. Equating the finite difference approximation of the fourth derivative of the sequence to a constant means that the values of the sequence are predicted by a fourth-order polynomial. The 21 values of Liocourt's sequence are indeed given by a fourth-order polynomial (Appendix A). Contrary to Kerr's model, this model predicts the change from 1 to 2 trees in Liocourt's table for the largest diameter class.

Although Kerr's model and the fourth-order polynomial model predict exactly the same sequence of numbers, the expansion of this sequence along rows or along columns correspond to different numbers (Table 1). Independently of the value used for the boundary condition, Kerr's sequence converges, as the number of columns goes to infinity, to a geometric series with ratio $q=2$. On the contrary, the sequence based on the polynomial model grows to infinity as the class index $i$ increases to infinity.

In his 1900 manuscript, Liocourt again presented a sequence of numbers of trees in successive diameter classes, but he explicitly introduced the $q$ ratio and the geometric model to compute this sequence. In Table $\mathrm{C}$ at page 13, Liocourt computed "the ratio between the number of trees in the different diameter classes" (Fig. 1), and he noticed at page 14: "these ratios are approximately constant, for all forest types and all diameters". The mean ratio was 1.4 (page 14).

\section{Discussion and conclusion}

At least two methods can be used to reconstruct the exact sequence of numbers given by Liocourt in the table at the page 403 of his publication of 1898: by successively adding columns starting from a column of ones (Kerr 2014), or by successively adding rows starting from four initial values. Although these two building methods bring the same table of numbers when boundary conditions are adequately set, the numbers on the first column of this table differ from the numbers on successive columns to the left (Table 1). While we do not know how Liocourt proceeded, there are several hints that make us believe that Liocourt built his table from left to right as we propose here (and as is common in the occidental culture) rather than from right to left as proposed by Kerr. First, the rightmost column in the table published in 1898 by Liocourt is actually a column of zeros and not a column of ones. This rightmost column of zeros makes sense as the difference between the ones in the column to its left, but it does make sense when considering the column of ones as the starting point of the table. Second, Liocourt built his table for 21 diameter classes while observations were available for the 17 largest classes only (Table 1). With Kerr's method that builds the table from bottom to top using the numbers in the 21 st row as boundary conditions, there is no reason for adding four rows below the minimum diameter of inventory. With the row-wise method on the contrary, the four rows below the minimum diameter of observations are needed as a boundary condition to initiate the sequence. Third, and more importantly, Liocourt aimed at modelling an observed diameter distribution, so that the starting point to build the table must have been these observations. Liocourt indicated in his text in 1898 that the predicted distribution could be fitted to observations (p. 404, first paragraph). The column-wise method by Kerr is easier to implement, but it does not provide any degree of freedom for fitting to observations. A degree of freedom for model fitting could actually be introduced by generalizing equation (1) as: $(q-1) N_{i j}=N_{i-1, j-1}-N_{i, j-1}$, where $q$ is to be estimated. Using the same algorithm as Kerr (2014), the asymptotic sequence then is a geometric series with ratio $q$. Nevertheless, these considerations on geometric series with any ratio are not present in Liocourt's article of 1898 . The fitting of the model to observations rather advocates that Liocourt built his table from left to right, adjusting values in the first column until the fourth-order finite difference be equal to one, which is equivalent with fitting a fourthorder polynomial. The polynomial model provides a great 
flexibility of shapes but predicts unrealistic values (and even possibly negative values) when extrapolated outside the range of observations.

The $q$ ratio and the geometric series for the number of trees in diameter classes were definitely introduced by Liocourt in his manuscript of 1900 . As pointed out by Kerr (2014), the 1898 article was inappropriately referred to in the literature, mostly in English, from early texts that cited it (Meyer and Stevenson 1943; Smith 1962). However, scientists who had access to the 1900 manuscript also correctly referred to it, even recently, when elaborating on the $q$ ratio (Chevrou 1990; Buongiorno et al. 1996; Bastien and de Turckheim 1999). Scanned copies of Liocourt's 1898 article and 1900 handwritten manuscript are now available on the web (see permanent URLs in the references).

\section{Compliance with Ethical Standards}

Funding This study was not supported by any funding

$$
\begin{array}{rlrl}
N_{i 5}= & & (j=5) \\
N_{i 4}= & 22-i & & (j=4) \\
N_{i 3}= & \frac{1}{2} i^{2}-\frac{43}{2} i+232 & & (j=3) \\
N_{i 2}= & -\frac{1}{6} i^{3}+\frac{21}{2} i^{2}-\frac{664}{3} i+1563 & & (j=2) \\
N_{i 1}= & \frac{1}{24} i^{4}-\frac{41}{12} i^{3}+\frac{2531}{24} i^{2}-\frac{17449}{12} i+7569 & (j=1) \\
N_{i 0}= & -\frac{1}{120} i^{5}+\frac{5}{6} i^{4}-\frac{803}{24} i^{3}+\frac{4051}{6} i^{2}-\frac{102893}{15} i+28128 & (j=0) \\
N_{i,-1}= & \frac{1}{720} i^{6}-\frac{13}{80} i^{5}+\frac{1145}{144} i^{4}-\frac{10013}{48} i^{3}+\frac{1116197}{360} i^{2} & & (j=-1) \\
& -\frac{372161}{15} i+83722 & & \\
N_{i,-2}= & -\frac{1}{5040} i^{7}+\frac{19}{720} i^{6}-\frac{1087}{720} i^{5}+\frac{6947}{144} i^{4}-\frac{335471}{360} i^{3} & & (j=-2) \\
& +\frac{3926603}{360} i^{2}-\frac{30169913}{420} i+205987 &
\end{array}
$$

and so on. In particular, Liocourt's sequence corresponds to $j=1$.

\section{References}

Bastien Y, de Turckheim B (1999) Points de vue sur l'aménagement en futaie irréguliére. Rev For Fr 51(numéro spécial):65-86. doi:10.4267/2042/5506

Buongiorno J, Peyron JL, Valdenaire JM, Bruciamacchie M (1996) Croissance et aménagement de la futaie jardinée du Jura : stratégies de gestion et structure des peuplements. Rev For Fr 48(1):49-61. doi:10.4267/2042/26727

Chevrou RB (1990) La loi tronquée de de Liocourt. Ann Sci For 47(3):229-239. https://hal.archives-ouvertes.fr/hal-00882703

Kerr G (2014) The management of silver fir forests: de Liocourt (1898) revisited. Forestry 87(1):29-38. doi:10.1093/forestry/cpt036
Liocourt F (1898) De l'aménagement des sapinières. Bull Soc For Franche-ComtéBelfort 6:369-405. http://infodoc.agroparistech.fr/ index.php?lvl=notice_display\&id=181924

Liocourt F (1900) Sapinières. Manuscript held in the library of the École Nationale du Génie Rural Eaux et Forêts, Nancy. http:// infodoc.agroparistech.fr/index.php?lvl=notice_display\&id=91142

Marín-Pageo F, Rapp-Arrarás Í (2013) The application of the Liocourt model to uneven-aged cork oak stands. Ital J For Mt Environ 68(2):85-93. doi:10.4129/ifm.2013.2.03

Meyer HA, Stevenson DD (1943) The structure and growth of virgin beech-birch-maple-hemlock forests in Northern Pennsylvania. J Agric Res 67:465-484

Schaeffer A, Gazin A, d'Alverny A (1930) Sapinières. Le jardinage par contenance (méthode du contrôle par les courbes). Les Presses Universitaires de France, Paris. http://gallica.bnf.fr/ark:/ 12148/bpt6k6441699s

Smith DM (1962) Practice of silviculture, 7th edn. Wiley, New York

Vannière B (1977) Influence de l'environnement économique sur l'aménagement forestier en Afrique tropicale. Bois For Trop 175:3-14 